\title{
Tata Laksana Epistaksis Berulang pada Anak
}

\author{
Bidasari Lubis, Rina A C Saragih \\ Bagian Ilmu Kesehatan Anak FK-USU / RS H. Adam Malik Medan
}

\begin{abstract}
Epistaksis berulang selalu menimbulkan kecemasan pada orang tua dan seringkali menjadi keluhan yang menyebabkan seorang anak dibawa berobat ke unit rawat jalan. Etiologi epistaksis dapat dibagi atas penyebab lokal dan sistemik, namun pada umumnya kasus epistaksis idiopatik. Diagnosis dan penanganan epistaksis bergantung pada lokasi dan penyebab perdarahan. Diagnosis ditegakkan berdasarkan anamnesis, pemeriksaan fisis, dan pemeriksaan penunjang. Pemeriksaan penunjang sesuai dengan indikasi dapat yaitu pemeriksan laboratorium darah, radiografi, endoskopi, CT scan dan biopsi. Tata laksana mencakup resusitasi jika diperlukan, penekanan dengan jari, tampon anterior, kauterisasi, tampon posterior dan, pembedahan. Saat ini terdapat berbagai alternatif terapi seperti krim antiseptik, petroleum jelly, kauterisasi silver nitrate, embolisasi angiografi, fibrin glue, endoscopic electrocautery, irigasi air panas, dan laser (Sari Pediatri 2007; 9(2):75-79).
\end{abstract}

Kata kunci: epistaksis, kauterisasi

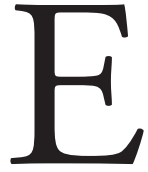
pistaksis sering dijumpai pada anak dan angka kejadian epistaksis menurun setelah pubertas. ${ }^{1}$ Epistaksis atau perdarahan dari hidung, dijumpai pada $60 \%$ dari populasi umum, insiden terbanyak pada usia kurang dari 10 tahun dan lebih dari 50 tahun. ${ }^{2}$ Seringkali seorang anak dibawa berobat ke Unit Rawat Jalan dengan keluhan perdarahan dari hidung yang berulang. Tidak bergantung pada tingkat keparahan perdarahan, hal ini selalu menimbulkan kecemasan pada orang tua. ${ }^{3}$

\footnotetext{
Alamat korespondensi

Dr. Bidasari Lubis, SpA(K).

Bagian Ilmu Kesehatan Anak FK USU/RS HAM Jalan Bunga Lau No. 17 Telepon : (061) 8361721, Fax : (061) 8361721

E-mail : bikafkusu@telkom.net; kotak Pos 697 Medan - 20136
}

Suatu penelitian cross-sectional terhadap 1218 anak usia 11-14 tahun melaporkan bahwa 9\% mengalami episode epistaksis sering. ${ }^{4}$

Berdasarkan atas daerah asal perdarahan epistaksis dibagi atas dua kategori, yaitu epistaksis anterior dan posterior. ${ }^{5}$ Daerah asal perdarahan yang paling sering adalah pleksus Kiesselbach, yaitu daerah septum anterior tempat pembuluh darah yang berasal dari arteri karotid internal dan karotid eksternal bertemu. Daerah ini memiliki mukosa tipis sehingga rentan terhadap paparan udara dan trauma. ${ }^{1,6}$

Diagnosis dan penanganan epistaksis bergantung pada lokasi dan penyebab perdarahan. ${ }^{1}$ Kebanyakan kasus epistaksis (80\%-90\%) merupakan idiopatik. ${ }^{7}$ Epistaksis idiopatik berulang adalah perdarahan dari hidung dan berulang, self limiting, yang penyebab 
spesifik tidak diketahui. Tidak ada konsensus tentang frekuensi atau keparahan rekurensi. ${ }^{4}$

Penyebab epistaksis dapat berupa penyebab lokal maupun sistemik. Penyebab lokal termasuk epistaksis idiopatik, trauma, inflamasi, neoplasia, vaskular, iatrogenik, kelainan struktural, dan obat-obatan seperti semprot hidung. Penyebab sistemik berupa kelainan hematologi, lingkungan (temperatur, kelembaban dan ketinggian), obat-obatan (contoh antikoagulan), gagal organ (uremia dan gagal hati), serta penyebab lain misalnya hipertensi. ${ }^{7}$ Sandoval $\mathrm{dkk}^{8}$ yang meneliti 178 anak dengan epistaksis berulang mendapati bahwa sepertiga di antaranya didiagnosis koagulopati, dan penyakit Von Willebrand yang ditemukan pada 33 pasien.

\section{Diagnosis}

Pada sebagian besar kasus, penyebab epistaksis sudah dapat ditentukan melalui anamnesis dan pemeriksaan fisis. ${ }^{2}$ Bila tidak dijumpai kehilangan darah yang berat, tidak ada kecurigaan faktor sistemik dan lokasi perdarahan anterior telah dapat ditentukan, tidak diperlukan pemeriksaan laboratorium. Perlu diingat bahwa seringkali penyebab perdarahan ringan berulang merupakan idiopatik. Namun, pada pasien yang sumber perdarahan atau kelainan lokal tidak jelas dapat dinyatakan idiopatik hanya jika pendekatan untuk mencari kelainan primer telah dilakukan dan tidak didapati kelainan. ${ }^{7}$

Pada anamnesis harus ditanyakan tentang awal terjadinya perdarahan, riwayat perdarahan sebelumnya, penyakit penyerta, pemakaian obat-obatan seperti aspirin atau warfarin, serta riwayat kelainan darah atau leukemia dalam keluarga. ${ }^{2,5}$ Kebanyakan perdarahan dari hidung diakibatkan oleh trauma ringan pada septum nasal anterior, oleh karena itu anamnesis harus mencakup kemungkinan tersebut. ${ }^{5}$ Riwayat perdarahan hidung berulang yang sering, disertai mudah memar, atau perdarahan lainnya memberikan kecurigaan terhadap penyebab sistemik dan dianjurkan penjajakan hematologis. ${ }^{5,10}$

Pada pemeriksaan fisis, setelah memeriksa keadaan umum pasien dan memastikan tanda vital stabil, perhatian diarahkan pada hidung. ${ }^{3}$ Hidung harus diperiksa dengan teliti untuk menentukan lokasi dan penyebab perdarahan. ${ }^{6}$ Lampu kepala atau cermin kepala, dan spekulum nasal sebaiknya digunakan untuk visualisasi yang optimal. ${ }^{2}$ Jika pasien mengalami trauma nasal, perhatikan adanya septal hematoma, yang tampak berupa masa hitam kebiruan pada septum anterior memenuhi kavum nasal. Terkadang dapat

Tabel 1. Hasil skrining perdarahan dengan kemungkinan diagnosis. ${ }^{11}$

\begin{tabular}{ll}
\hline Hasil & Diagnosis yang mungkin \\
\hline aPTT memanjang & Von Willebrand disease* \\
PT/fibrinogen/trombosit normal & Defisiensi faktor VIII \\
& Defisiensi faktor IX \\
& Defisiensi faktor XI \\
PT memanjang & Pemakaian warfarin \\
aPTT/fibrinogen/trombosit normal & Defisiensi vitamin K dini \\
& Gangguan awal fungsi hati \\
& Defisiensi faktor VII \\
PT dan aPTT memanjang & Warfarinisasi berlebih \\
Fibrinogen/trombosit normal & Defisiensi vitamin K berat \\
& Heparinisasi berlebih \\
& Defisiensi faktor X, V atau protrombin \\
PT dan aPTT memanjang & Acquired inhibitors \\
Fibrinogen menurun & Gangguan hati berat \\
Trombosit normal atau menurun & Dysfibrinogenaemia/afibrinogenaemia \\
* von Willebrand disease subtipe 2B berhubungan dengan trombosit yang menurun, aPTT tidak selalu \\
memanjang
\end{tabular}

Dikutip dari: Thomas AE. The bleeding child; is it NAI?. Arch Dis Child 2004; 89: 1163-7 
dilihat hemangioma mukosa atau teleangiektasi. Jika tidak dijumpai sumber perdarahan namun dijumpai darah yang mengalir di tenggorokan, kemungkinan asal perdarahan dari daerah posterior., ${ }^{5,11}$

Perhatikan apakah terdapat hemangioma atau teleangiektasia pada kulit, yang dapat juga dijumpai dalam kavum nasal. Jaundice, petekie, purpura, limfadenopati, dan hepatosplenomegali dapat mengarahkan pada gangguan perdarahan. Pucat, takikardi, irama gallop, atau perubahan ortostatik tanda vital dapat menunjukkan kehilangan darah yang signifikan. ${ }^{11}$ Tekanan darah yang tinggi, meskipun jarang, dapat menyebabkan epistaksis. ${ }^{5}$
Pada sebagian besar kasus, perdarahan hidung pertama kali ataupun yang tidak sering berulang, tidak diperlukan pemeriksaan laboratorium jika disertai dengan adanya riwayat trauma. Jika dicurigai kehilangan darah yang bermakna, leukemia ataupun keganasan, perlu dilakukan pemeriksaan darah lengkap. Jika dicurigai adanya koagulopati, dilakukan pemeriksaan darah lengkap, prothrombin time (PT), activated partial thromboplastin time (aPTT), dan waktu perdarahan. ${ }^{5}$ Skrining perdarahan dengan kemungkinan diagnosis tertera pada Tabel $1 .{ }^{11}$

Pemeriksaan radiografi dapat memperlihatkan sinusitis akut, fraktur, atau keganasan pada sinus

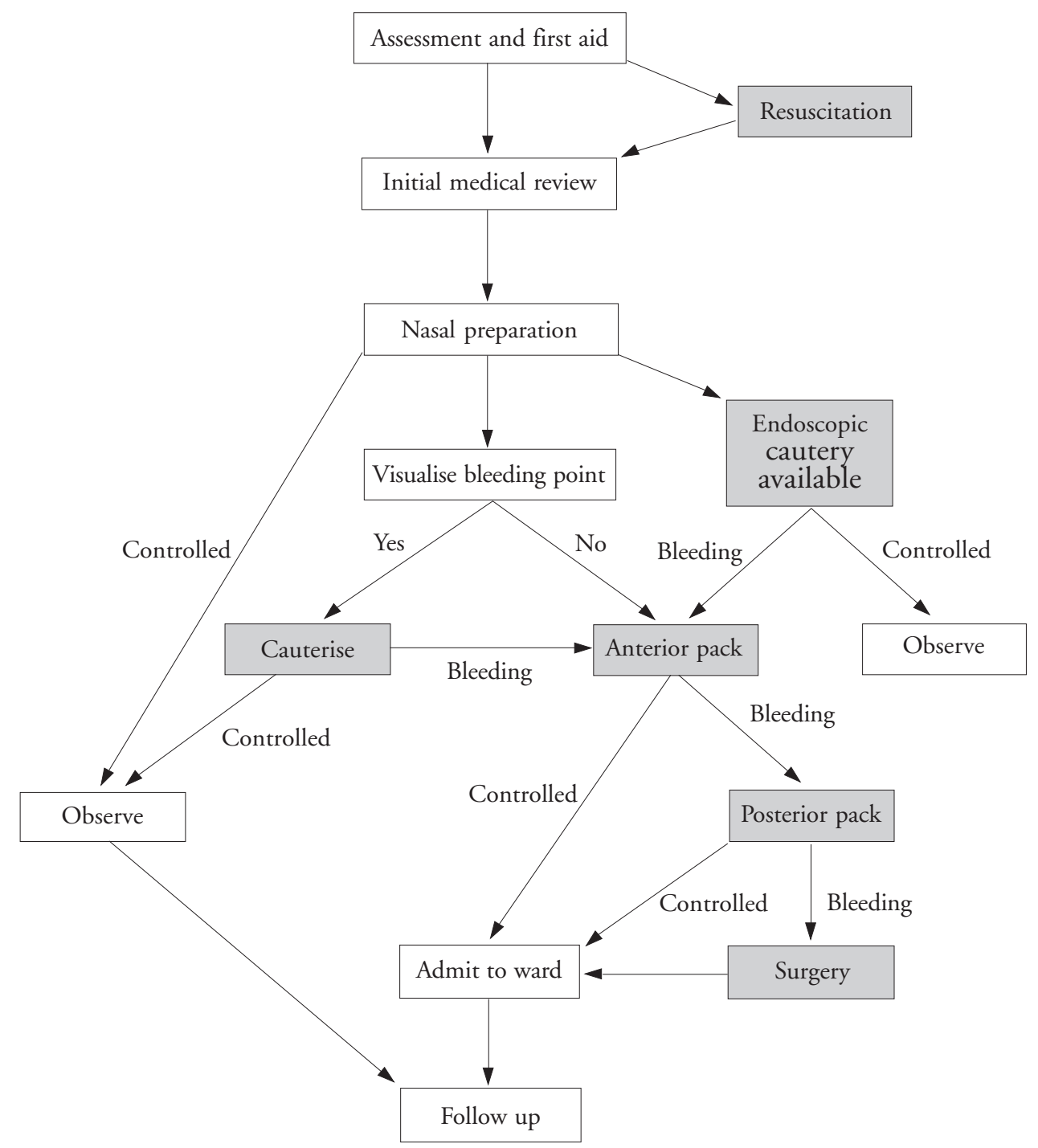

Gambar 1. Protokol tata laksana epistaksis ${ }^{7}$ 
2. Kucik CJ, Clenney T. Management of epistaxis. Am Fam Physician 2005; 71: 305-11.

3. Chadha SK. Epistaxis in children. Didapat dari: http:// www.indegene.com/Ent/FeatArt/indEntFeatArt8. html.

4. Garry G. Nosebleeds in children. Clin Evid 2005; 13:1-2.

5. Gluckman W. Epistaxis. Didapat dari: http:// www.emedicine.com/ped/topic/618.htm.l

6. Handler SD, Myer CM. The nose and paranasal sinuses. Dalam: Rudolph AM, Hoffman JIE, Rudolph CD, penyunting. Rudolph's pediatrics. Edisi ke-20. London: Prentice Hall International; 1996. h. 953-8.

7. Pope LER, Hobbs CGL. Epistaxis: an update on current management. Postgrad Med J 2005; 81: 309-14.

8. Sandoval C, Dong S, Visintainer P, Fevzi O, Somasundaram J. Clinical and laboratory features of 178 children with recurrent epistaxis (Abstrak). J Pediatr Hematol/Oncol 2002; 24: 47-9.

9. Vora A, Makris M. An approach to investigation of easy bruising. Arch Dis Child 2001; 84: 488-91.

10. Keller J. ENT Emergencies. Dalam: Crain EF, Gershel JC, penyunting. Clinical manual of emergency pediatrics. Edisi ke-4. New York: McGraw-Hill; 2003. h. 132-5.

11. Thomas AE. The bleeding child; is it NAI?. Arch Dis Child 2004; 89: 1163-7.

12. Bhargava KB, Bhargava SK, Shah M. A short textbook of E.N.T diseases for students and practitioners. Edisi ke-5. Mumbai: Usha Publications;1999. h. 225-31.

13. Randall DA. The nose and paranasal sinuses. Dalam: Lee KJ, penyunting. Essential otolaryngology head \& neck surgery. Edisi ke-8. New York: 2003. h.714-6.
14. Dasmarinas, De La Salle University Health Sciences Campus College Of Medicine Department Of Otolaryngology-Head \& Neck Surgery. Epistaxis. Diunduh dari: http://www.hsc.dlsu.edu.ph/entlepistaxis.htm.

15. Johnson CE, Kelley P, Friedman N, Chan K, Berman S. Ear, nose, \& throat. Dalam: Hay WW, Hayward AR, Levin MJ, Sondheimer JM. Current pediatric diagnostic \& treatment. Edisi ke-16. New York: McGraw-Hill; 2003. h. 479-84.

16. Burton MJ, Doree CJ. Interventions for recurrent idiopathic epistaxis (nosebleeds) in children (Cochrane review) (Abstrak). The Cochrane Library, Issue 4, 2005.

17. Kubba H, MacAndie C, Botma M. A prospective, single blind, randomized controlled trial of antiseptic cream for recurrent epistaxis in childhood. Clin. Otolaryngol 2001; 26: 465-8. Dikutip oleh Garry G.

18. Ruddy J, Proops DW, Pearman K. Management of epistaxis in children. Int J Paediatr Otorhinolaryngol 1991; 21:139-42. Dikutip oleh Garry G. Nosebleeds in children. Clin Evid 2005; 13:1-2.

19. Loughran S, Spinou E, Clement WA, Catheart R, Kubba $\mathrm{H}$, Geddes NK. A prospective, single blind, randomized controlled trial of petroleum jelly/Vaseline for recurrent paediatric epistaxis (Abstrak). Clin Otolaryngol 2004; 29:266-9.

20. Hopf M, Hopf JUG, Rohde E, Muller G, Scheller EE, Scherer H. Endoscopically controlled laser therapy of recurrent epistaxis with the $940 \mathrm{~nm}$ diode laser. Med. Laser Appl 2002; 17:231-4. 
paranasal. Endoskopi memungkinkan visualisasi dan tata laksana (dengan suction cautery) perdarahan posterior. Pemeriksaan $C T$ scan dan biopsi diperlukan jika terdapat kecurigaan tumor intranasal, misalnya nasopharyngeal carcinoma. ${ }^{13,14,15}$ Angiofibroma nasofaring dapat menyebabkan epistaksis berulang, hal ini sering dijumpai pada remaja laki-laki. Dalam hal ini pemeriksaan $C T$ scan kavum nasal merupakan sarana diagnostik yang perlu dilakukan. ${ }^{16}$

\section{Tata Laksana}

Epistaksis merupakan keadaan yang dapat mengancam nyawa. Pasien dengan perdarahan aktif membutuhkan pemeriksaan lengkap dan resusitasi jika diperlukan. Tanda vital harus diawasi secara teratur. Selama resusitasi, pada umumnya perdarahan dapat dikendalikan dengan penekanan jari. ${ }^{7}$ Penekanan pada mumnya dapat menghentikan perdarahan anterior. Jepit cuping hidung bersamaan selama 5 menit sementara anak duduk tegak (untuk menghindari tertelannya darah). Jika tidak berhasil, basahi kapas dengan epinefrin 1:1000 atau oxymetazoline dan tempatkan pada kavum nasal. Pilihan lain dapat diberikan petrolatum-impregnated gauze, merocel, atau gelfoam. Setelah darah membeku, berikan anastesi topikal dengan lidokain $4 \%$ atau benzokain dan kauter lokasi perdarahan dengan nitrat silver, khususnya dilakukan pada perdarahan berulang. Terapi hemangioma atau teleangiektasia dengan cara yang sama, tetapi jangan menggunakan kauter jika terdapat kecurigaan gangguan perdarahan. ${ }^{11}$

Humidifikasi, tetes hidung, dan penggunaan petrolatum (vaseline) pada septum sebelum tidur membantu mengurangi rekurensi. Jika tindakan rutin tidak efektif atau sumber perdarahan posterior, gunakan tampon posterior, metode tampon pada umumnya dilakukan oleh ahli otolaringologi. ${ }^{11}$ Perdarahan yang tidak dapat dihentikan dengan penatalaksanaan non bedah membutuhkan tindakan pembedahan. ${ }^{7}$ Pilihan terapi lainnya berupa embolisasi angiografi, fibrin glue, endoscopic electrocautery, irigasi air panas, dan laser. ${ }^{7}$ (Gambar 1)

Terdapat beberapa penelitian yang membandingkan berbagai intervensi pada epistaksis idiopatik berulang yaitu penggunaan krim antiseptik, petroleum jelly, dan kauterisasi silver nitrate. Namun analisis sistematik oleh Burton dkk. ${ }^{17}$ terhadap penelitian tersebut mendapatkan bahwa tata laksana yang optimal untuk epistaksis idiopatik berulang pada anak belum diketahui. Kubba dkk ${ }^{18}$ mengemukakan bahwa krim antiseptik (krim chlorhexidine/neomycin) mengurangi perdarahan dari hidung dibandingkan tanpa pengobatan. Penelitian lain oleh Ruddy $\mathrm{dkk}^{19}$ menemukan tidak ada perbedaan bermakna antara krim antiseptik dengan kauter silver nitrate. Longhran $\mathrm{S}^{20}$ dalam penelitiannya menemukan bahwa tidak ada perbedaan bermakna dalam penyembuhan sempurna epistaksis berulang antara petroleum jelly dengan tanpa pengobatan.

Epistaksis berulang dapat ditangani dengan tepat dengan pembedahan laser. Oleh karena perdarahan iatrogenik dapat dihindari, pendekatan ini memiliki kelebihan dibandingkan yang lain dalam hal mempertahankan struktur anatomi serta waktu pengobatan. Hopf $\mathrm{dkk}^{21}$ melaporkan penggunaan terapi laser pada epistaksis berulang dengan $940 \mathrm{~nm}$ diode laser dan mendapati hasil yang tidak berbeda dibandingkan laser Argon.

Berbagai penyebab epistaksis berulang memerlukan tindakan khusus. Infeksi dan peradangan mukosa hidung membutuhkan terapi dengan dekongestan dan antibiotik. Pada kasus epistaksis akibat kelainan darah, pendekatan masalah lokal maupun sistemik harus dilakukan bersamaaan. ${ }^{3}$ Dalam tata laksana epistaksis, penyebab primer harus diterapi setelah kedaruratan teratasi. $^{3}$

\section{Ringkasan}

Epistaksis berulang merupakan keluhan yang sering dijumpai pada anak. Terdapat berbagai kemungkinan penyebab epistaksis, baik lokal maupun sistemik. Dibutuhkan anamnesis dan pemeriksaan fisis yang cermat, serta pemeriksaan penunjang yang tepat untuk menentukan penyebab sehingga dapat dilakukan tata laksana yang tepat.

\section{Daftar Pustaka}

1. Haddad J. Acquired disorders of the nose. Dalam: Behrman RE, Kliegman RM, Jenson HB, penyunting. Nelson textbook of pediatrics. Edisi ke-17. Philadelphia: Saunders; 2004. h. 1387-8. 